\title{
DESENVOLVIMENTO E AVALIAÇÃO DE UM PORTA-AMOSTRA DE BAIXO CUSTO PARA CARACTERIZAÇÃO ELÉTRICA DE MATERIAIS CERÂMICOS
}

\author{
Luiz Rogério Pinho de Andrade Lima*, Shayenne Diniz da Nóbrega e Carmel Suzarte Ayres Vasconcelos \\ Departmento de Ciência e Tecnologia dos Materiais, Escola Politécnica, Universidade Federal da Bahia, Rua Aristides Novis, 2, \\ 40210-630 Salvador- BA, Brasil \\ Iuri Muniz Pepe e Luiz Carlos Simões Soares Júnior \\ Departamento de Física Geral, Instituto de Física, Universidade Federal da Bahia, Campus Universitário de Ondina, 40210-340 \\ Salvador-BA, Brasil
}

Recebido em 15/8/09; aceito em 13/12/09; publicado na web em 3/5/10

\begin{abstract}
DEVELOPMENT AND EVALUATION OF A LOW COST SAMPLE HOLDER FOR ELECTICAL CHARACTERIZATION OF CERAMICS. Conventional sample holder cells used to the electric characterization of ceramics at high temperature consists of an alumina tube and platinum wires and plates using a complex design. The high cost materials used in the conventional sampler holder cell were replaced by stainless steel and conventional ceramics. The sample holder was validated by characterizing yttria-stabilizedzirconia in a temperature range of 25 to $700{ }^{\circ} \mathrm{C}$. The results do not present variations, discontinuity or unusual noise in the electric signals. Several samples were characterized without maintenance, which demonstrates that the sample holder is electric and mechanic adequate to be used to electrical characterization of ceramics up to $700{ }^{\circ} \mathrm{C}$.
\end{abstract}

Keywords: sample holder; solid oxide fuel cell; impedance spectroscopy.

\section{INTRODUÇÃO}

Atualmente várias pesquisas na área de pilha a combustível de eletrólito sólido vêm sendo realizadas visando reduzir a temperatura de operação e aumentar a vida útil das pilhas. A caracterização elétrica de materiais cerâmicos tem recebido particular atenção neste contexto, pois alguns materiais exibem acentuada condução iônica em temperaturas intermediaria (entre 500 e $\left.700{ }^{\circ} \mathrm{C}\right) .{ }^{1-10} \mathrm{~A}$ caracterização de cerâmicas condutoras e a avaliação do efeito de aditivos e dopantes em temperaturas intermediárias é fundamental para o entendimento do funcionamento e otimização do emprego destes materiais. ${ }^{2-4}$

Os porta-amostra convencionalmente usados para a caracterização de amostras de cerâmicas condutoras em altas temperaturas consistem em suportes de alumina e eletrodos e fios de platina que, embora sejam eficazes, são de alto custo e montagem relativamente complexa ${ }^{6,9,10}$ o que torna o seu uso proibitivo para grupos emergentes e usuários eventuais.

Neste trabalho, foi desenvolvido um porta-amostra que permite introduzir discos de materiais cerâmicos no interior de fornos, visando a realização de medidas elétricas. Para isto houve substituição de materiais de custo elevado, como platina e alumina, por materiais convencionais, especificamente aços inoxidáveis e cerâmicas convencionais, assim como o uso de uma configuração de montagem simples, o que facilita a manutenção do aparato. O porta-amostra desenvolvido tem como funcionalidade suportar de forma fixa e segura amostras de cerâmica na forma de pastilhas circulares, com diâmetro de até $20 \mathrm{~mm}$, que são conectadas eletricamente com fontes de excitação que também funcionam como medidores de tensão e de corrente. Um aspecto importante no desenvolvimento deste componente de instrumentação foi assegurar baixo custo e simplicidade nos materiais empregados em sua construção, o que facilita tanto a sua fabricação quanto a sua manutenção. Na validação do porta-amostra foram caracterizadas amostras de zircônia estabilizada com ítria (YSZ) para temperaturas de até $700{ }^{\circ} \mathrm{C}$ usando fonte de corrente-tensão continua e posteriormente alternada.

*e-mail: 1elo@ufba.br

\section{PARTE EXPERIMENTAL}

O forno usado para a preparação e caracterização de amostras de cerâmicas condutoras é do tipo tubular (Carbolite, modelo STF 16/-/180 com controlador digital PID 301), com os elementos resistivos de aquecimento de zircônia montados ao redor de um tubo de alumina que serve de suporte aos materiais a serem aquecidos. Este forno é construído ao redor de um tubo de alumina de $49 \mathrm{~mm}$ de diâmetro e $900 \mathrm{~mm}$ de comprimento, podendo alcançar uma temperatura de $1600{ }^{\circ} \mathrm{C}$. O controlador digital permite a seleção de patamares de temperatura e taxas de aquecimento convenientes para a sinterização ou a caracterização das amostras. $\mathrm{O}$ tubo que recebe a amostra é de alumina e para evitar perda de calor por radiação e correntes de convecção a entrada posterior do tubo é lacrada com um tampão refratário. Note que um porta-amostra para ser usado neste tipo de forno deve ser capaz de resistir à temperatura do centro do forno, assim como ao gradiente de temperatura que se estabelece ao longo do tubo de alumina.

A estrutura do porta-amostra desenvolvido está representado nas Figuras 1a e 1b. Ele é baseado no empilhamento espaçado de cinco discos de cerâmica e três discos vazados de aço galvanizado. A fixação destas estruturas circulares entre elas, assim como o devido espaçamento, formando o corpo cilíndrico do porta-amostra, é feita por três barras rosqueadas de aço inoxidável AISI 304 com diâmetro de $3 \mathrm{~mm}$. Cada peça é fixada por seis porcas em aço inoxidável AISI 304, três arruelas de pressão asseguram a estabilidade da montagem, tanto ao longo do tempo e em presença de vibrações mecânicas, durante os ciclos de aquecimento e resfriamento. Os eletrodos de medição são feitos a partir de peças circulares maciças com 3,0 mm de espessura em aço inoxidável AISI 430, cujas faces são polidas. Sobre estes eletrodos foram dispostas duas telas quadradas de aço inoxidável AISI 316 de aresta igual a 2,0 cm e abertura de $0,5 \mathrm{~mm}$ para melhorar o contato da superfície da amostra com o eletrodo. Os eletrodos foram fixados aos discos de cerâmica por um parafuso central, que também serve de contato elétrico. Um par de fios de aço inoxidável é conectado aos eletrodos, usados para fazer as medidas elétricas. 


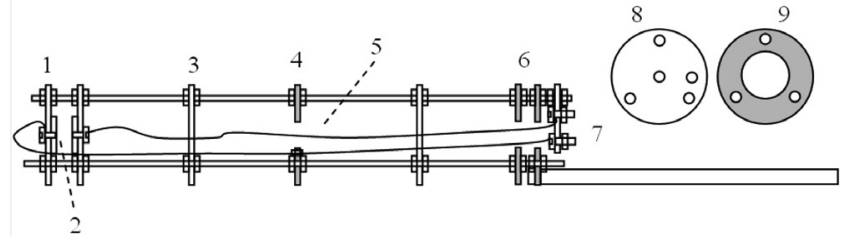

(a)

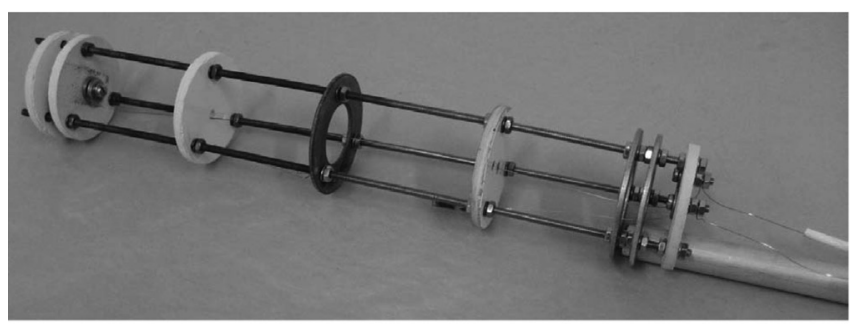

(b)

Figura 1. Esquema e foto do porta-amostra: 1) Disco em cerâmica que serve de fixação para o eletrodo de aço inoxidável. 2) Eletrodo em aço inoxidável com diâmetro de $20 \mathrm{~mm}$ e espessura de $3 \mathrm{~mm}$ e telas de aço inoxidável com $20 \mathrm{~mm}$ de aresta. 3) Disco cerâmico de passagem do fio de aço inoxidável. 4) Disco em aço galvanizado que serve de estrutura mecânica do portaamostra. 5) Fio em aço inoxidável. 6) Discos metálicos vazados de fixação que formam a base do porta-amostra. 7) Disco de cerâmica de fixação dos contatos elétricos de medição e parafusos de contato elétrico. 8) Detalhe da furação dos discos de cerâmica (3 orifícios de fixação a 120\%). 9) Detalhe dos orifícios dos discos de metal (3 orifícios de fixação a 120\%). 10) Cabo de manipulação em alumínio (diâmetro de $12 \mathrm{~mm}$ )

O porta-amostra desenvolvido foi montado a partir de materiais facilmente encontrados no mercado de peças e componentes mecânicos. A base da montagem são três barras rosqueadas (M3) em aço inoxidável AISI 304 de $235 \mathrm{~mm}$ de comprimento. O material dessas barras foi definido em função da necessidade da montagem e desmontagem do porta-amostra depois de seguidos ciclos de aquecimento. Os aços inoxidáveis austeníticos e ferríticos usados resistem à oxidação até cerca de $700{ }^{\circ} \mathrm{C}$. No presente caso, foi possível notar um escurecimento das barras e dilatação após os experimentos, mas isto pode ser facilmente corrigido antes de cada novo experimento pelo polimento dos eletrodos e ajuste das porcas que fixam os eletrodos e as amostras.

No porta-amostra, as barras são fixadas, por uma de suas extremidades, a dois discos metálicos vazados com $44 \mathrm{~mm}$ de diâmetro externo e $32 \mathrm{~mm}$ de diâmetro interno em aço galvanizado, onde três furos a $120^{\circ}$ foram feitos sobre um diâmetro de $8 \mathrm{~mm}$. Um terceiro disco metálico, colocado no centro da montagem assegura a rigidez mecânica do dispositivo. Os discos metálicos de aço galvanizado são, na realidade, arruelas usadas para a fixação dos parafusos de base de postes de iluminação pública de até 7,0 $\mathrm{m}$ de altura que têm acentuada resistência à oxidação atmosférica. Estes discos foram perfurados com o auxílio de uma broca de aço rápido de $3,5 \mathrm{~mm}$.

Os discos de cerâmica servem de fixação para os eletrodos de aço inoxidável que fixam as amostras e, ao mesmo tempo, permitem as medições elétricas. É importante ressaltar o fato de que os dois últimos discos de cerâmica estão no centro do forno e têm que ser capazes de suportar temperaturas de até $700{ }^{\circ} \mathrm{C}$. A segunda função destes discos é de espaçador isolante para o par de fios de aço carbono usado nas medidas elétricas, impedindo o curto-circuito entre eles e as barras rosqueadas. Para altas temperaturas seria necessário um revestimento em cerâmica na forma de pequenas esferas - contas de cerâmica ou pérolas de vidro - para fazer o isolamento elétrico desses condutores. Note que um último disco de cerâmica é usado para a fixação dos parafusos de conexão dos condutores internos ao porta-amostra com os instrumentos de medição externos. Estes discos cerâmicos foram feitos a partir de azulejos convencionais usados em revestimento de paredes. Este material, além de ser de baixo custo, suporta temperaturas superiores a $1000{ }^{\circ} \mathrm{C}$.

Para fazer os discos em cerâmica foi usada uma serra copo diamantada com $50 \mathrm{~mm}$ de diâmetro. Esta ferramenta é própria para fazer orifícios circulares em rochas e cerâmicas, podendo trabalhar a seco ou na presença de um fluido de resfriamento. Em uma aplicação normal, a serra copo é usada para fazer uma perfuração, neste caso, inicialmente é feito um furo no ponto central do corte. Este furo serve de referência para o pino guia da serra copo. Na aplicação descrita neste trabalho, o azulejo foi solidamente fixado à plataforma de uma furadeira de bancada, o pino guia da serra foi retirado e o produto do corte foi o disco de cerâmica (diâmetro de $45 \mathrm{~mm}$ ) que restou no interior da serra copo. Depois de cortado, este disco recebeu ainda cinco furos de $3,18 \mathrm{~mm}$ (1/8 de polegada), três com $120^{\circ}$ de espaçamento, sobre um diâmetro de $32 \mathrm{~mm}$, um central e um a $10 \mathrm{~mm}$ da borda. Os furos foram feitos com a ajuda de uma broca de vídia, própria para perfurar materiais cimentos e cerâmicos usados na construção civil.

Neste trabalho, dois tipos de zircônia estabilizada com ítria foram usadas na preparação das amostras. A primeira é da marca Vetec e possui um conteúdo de $10 \% \mathrm{Y}_{2} \mathrm{O}_{3}$ em $\mathrm{ZrO}_{2}$, com uma área específica de $136 \mathrm{~m}^{2} / \mathrm{g}$ e foi usada nos experimentos de análise de impedância. A segunda é da marca Sigma Aldrich contendo 8\% de $\mathrm{Y}_{2} \mathrm{O}_{3}$ em $\mathrm{ZrO}_{2}$ e foi usada nos experimentos com corrente contínua. A sequência de preparação das amostras usadas para testar o portaamostra foi iniciada pela pesagem dos pós dos reagentes, que foram em seguida dispostos em um molde de aço com diâmetro de $22 \mathrm{~mm}$ e compactados em uma prensa hidráulica a $104 \mathrm{MPa}$. Após a prensagem, as pastilhas contendo zircônia estabilizada com ítria foram sinterizadas a uma temperatura de $1400{ }^{\circ} \mathrm{C}$ por $3 \mathrm{~h}$. O processo de sinterização seguiu um plano de aquecimento, com patamares de temperaturas nos intervalos de 100, 200, 400, 600, 1000 e $1400{ }^{\circ} \mathrm{C}$ e taxas de aquecimento entre 2 e $3,5^{\circ} \mathrm{C} / \mathrm{min}$. Após a sinterização, as amostras cerâmicas ficaram com um diâmetro de cerca de $20 \mathrm{~mm}$ e espessura $1,2 \mathrm{~mm}$.

Inicialmente, a resistência das amostras de YSZ sinterizadas foi avaliada em função da temperatura. Para isto foram aplicadas tensões contínuas e as correspondentes correntes foram medidas. As inclinações das retas foram determinadas e, usando-se a espessura e área da amostra, a resistividade foi calculada. Foi usada nestes testes uma fonte de corrente continua HP modelo 6181C e dois multímetros digitais ICEL modelos MD 6400 e MD 6450, que funcionaram como voltímetro (colocado em paralelo com a amostra) e amperímetro (colocado em série com amostra).

Também foi usada para caracterização das amostras de YSZ espectroscopia de impedância, que é uma técnica baseado na aplicação de uma tensão alternada e na medida das componentes real e imaginária da impedância com esta excitação. ${ }^{6}$ Esta técnica tem sido largamente utilizada para caracterizar materiais, especialmente cerâmicas condutoras desde $1969,{ }^{6,9,10}$ quando o mecanismo de condução de zircônia estabilizada com ítria foi investigado para as faixas de temperatura alta e intermediária (entre 400 e $1000{ }^{\circ} \mathrm{C}$ ). ${ }^{8,11}$

As amostras de zircônia estabilizada com ítria foram caracterizadas com um analisador de impedância (Solartron, Modelo 1260), conectado a um microcomputador através de um cabo GPIB-USB-HS (National Instruments, Modelo NI488.2) e controlado pelo programa ZPlot/ZView (Scribner Associates Inc.), que fornece simultaneamente o diagrama de Bode, módulo da impedância e ângulo de fase em função da frequência, e o diagrama de Nyquist, o oposto da parte imaginária da impedância (-Z') versus a parte real da impedância (Z'). No presente caso, as medidas foram feitas para frequências entre 1 
$\mathrm{Hz}$ e $10 \mathrm{MHz}$, na faixa de temperatura entre 25 e $700{ }^{\circ} \mathrm{C}$ e foi usada uma tensão media de 3,0 V e uma amplitude de $0,1 \mathrm{~V}$.

\section{RESULTADOS E DISCUSSÃO}

Neste trabalho foram analisadas as medidas de resistência de zircônia estabilizada com ítria entre as temperaturas de 25 e 700 ${ }^{\circ} \mathrm{C}$ com auxílio do porta-amostra. A Figura 2 mostra a relação entre tensão e corrente. Nota-se que entre as temperaturas de 100 a 400 ${ }^{\circ} \mathrm{C}$ os valores das resistências elétricas são praticamente iguais, pois a condutividade iônica no YSZ começa a se intensificar apenas a partir da temperatura de $400{ }^{\circ} \mathrm{C}$. A resistência elétrica no YSZ tende a reduzir com o aumento da temperatura, devido ao aumento da condutividade iônica do material, o que se deve à intensificação da formação de regiões de vacâncias de oxigênio em temperaturas mais elevadas. ${ }^{9}$

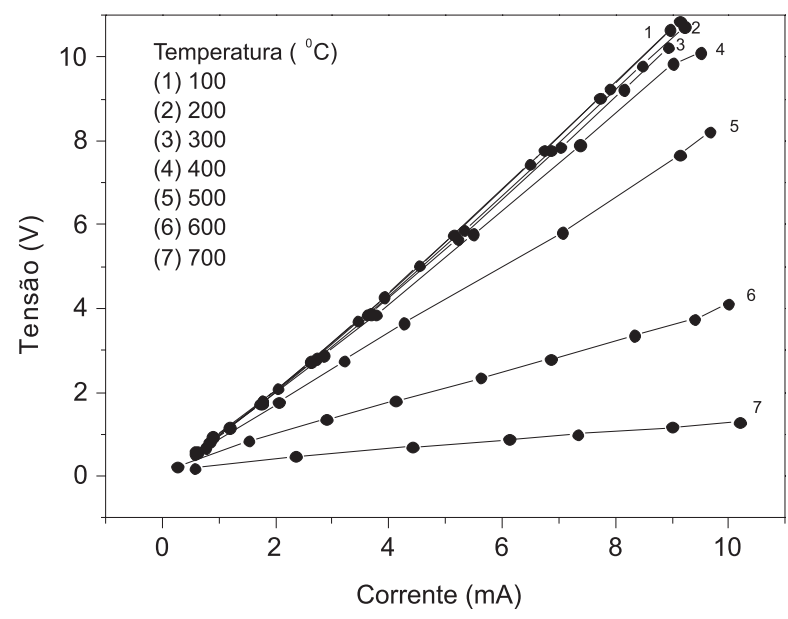

Figura 2. Gráfico da tensão em função da corrente para o YSZ entre as temperaturas de 100 a $700{ }^{\circ} \mathrm{C}$

A Figura 3 mostra a condutividade (ou seja, o inverso da resistividade) do YSZ em função da temperatura, avaliada através da aplicação de uma tensão contínua conhecida e a medida da corrente. Observa-se que até a temperatura de $400{ }^{\circ} \mathrm{C}$ a condutividade do YSZ apresenta um comportamento análogo para temperaturas baixas. Acima de $400{ }^{\circ} \mathrm{C}$, entretanto, a condutividade começa a aumentar, atingindo seu menor valor na temperatura de $700{ }^{\circ} \mathrm{C}$. Através do gráfico de Arrhenius é possível estimar a energia de ativação para o processo de condução a temperaturas baixa e intermediária como sendo, respectivamente, $0,023 \mathrm{e} 1,25 \mathrm{eV}$.

Também foi feita a análise de impedância das amostras de zircônia estabilizada com ítria entre as temperaturas de 25 e $700{ }^{\circ} \mathrm{C}$ com auxílio do porta-amostra. A Figura 4 representa o gráfico do plano de impedância (diagrama de Nyquist) para a zircônia estabilizada com ítria nas temperaturas de 500,600 e $700{ }^{\circ} \mathrm{C}$, o oposto da parte imaginária da impedância (-Z”) é representada como uma função da parte real da impedância (Z'). Todos os diagramas são compostos por dois semicírculos, correspondentes às regiões de baixa e alta frequência. Para a zircônia estabilizada com ítria a região de baixa frequência é a contribuição para a resistividade elétrica referente ao comportamento intergranular (resposta do contorno de grão), enquanto que a região de alta frequência é a contribuição para a resistividade elétrica referente ao comportamento intragranular (resposta do grão). ${ }^{69,10}$ Como esperado, a menor temperatura de caracterização tem a maior resistividade elétrica. Com o aumento da temperatura, o gráfico do plano de impedância (diagrama de Nyquist) tem seus

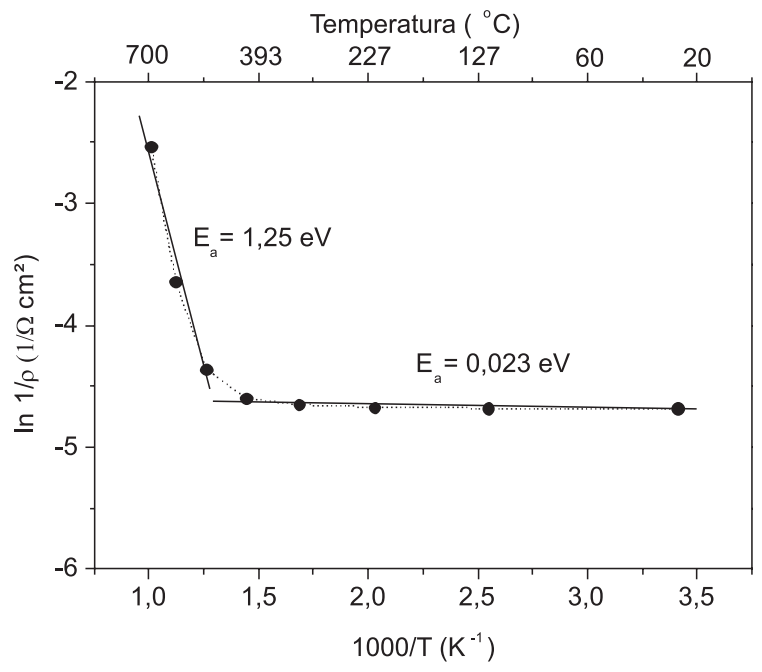

Figura 3. Energia de ativação para o YSZ nas temperaturas desde a temperatura ambiente até $700^{\circ} \mathrm{C}$

valores reduzidos, devido ao aumento da condutividade iônica. Isto acontece devido à formação das muitas regiões de densidade para a difusão de vacâncias de oxigênio, que são as cargas responsáveis pela condutividade elétrica. A região (de alta ou baixa frequência) que expressa o arco de maior diâmetro, caracteriza um comportamento mais capacitivo. A resistência total do eletrólito resulta no intercepto do eixo real à baixa frequência. , $^{10}$

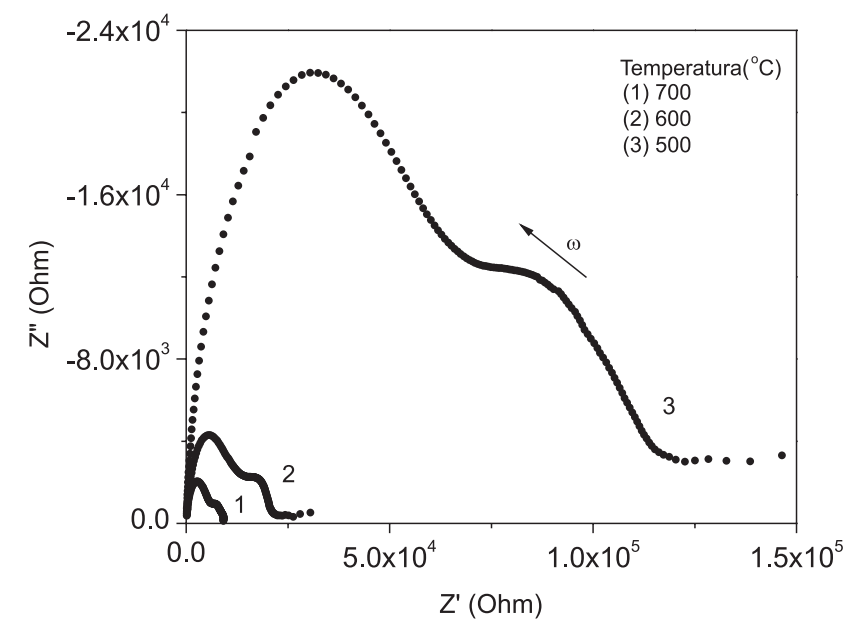

Figura 4. Diagramas de Nyquist referentes aos experimentos de espectroscopia de impedância para a zircônia estabilizada com ítria nas temperaturas de 500, 600 e $700^{\circ} \mathrm{C}$. A frequência $(\omega)$ varia de $10^{-2}$ a $10^{7} \mathrm{~Hz}$

A Figura 5 mostra o módulo da impedância em função da frequência, entre as temperaturas de 500 e $700{ }^{\circ} \mathrm{C}$. A frequência aumenta da direita para a esquerda entre $10^{-2}$ e $10^{7} \mathrm{~Hz}$. Observa-se que na temperatura de $700{ }^{\circ} \mathrm{C}$ apresenta menor módulo de impedância em todas as regiões de frequência, devido ao aumento da difusão dos elementos com a temperatura, além da resistência do contono de grão reduzir com o aumento da temperatura, contribuindo, desta maneira, para o aumento de troca iônica que, por sua vez, influencia diretamente no aumento da condutividade elétrica.

A condutividade elétrica na zircônia estabilizada com ítria é um processo ativado termicamente. O gráfico de Arrhenius pode ser usado para estimar a energia de ativação dos processos de transferência de carga. A Figura 6 mostra o efeito da temperatura sobre o 


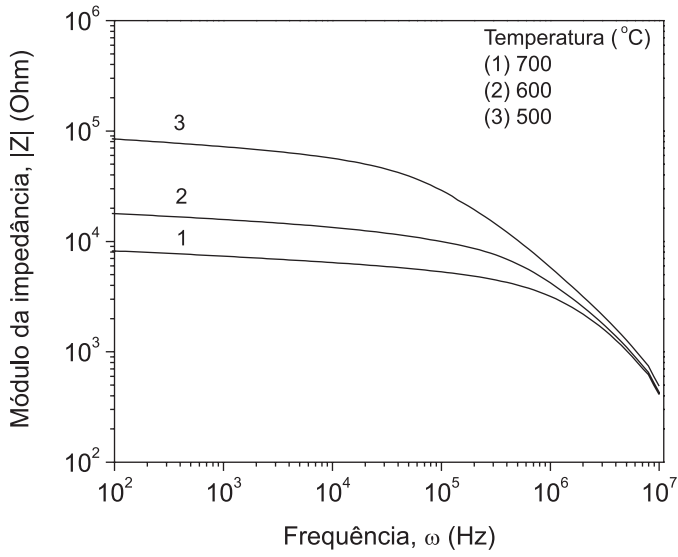

Figura 5. Módulo da impedância em função da frequência referente aos experimentos de espectroscopia de impedância para a zircônia estabilizada com ítria em função da temperatura $\left(500,600\right.$ e $\left.700{ }^{\circ} \mathrm{C}\right)$

módulo da impedância para dois valores de frequência $(\omega=0,1$ e 1,0 $\mathrm{MHz}$ ) para a zircônia estabilizada com ítria. A inclinação fornece a energia de ativação do processo que, neste caso, está associada com o movimento das lacunas de íons oxigênio e o transporte nas fronteiras dos grãos. ${ }^{6,9,10}$ Os resultados experimentais, para ambas frequências, apresentam um comportamento distinto para temperaturas baixas e intermediárias. Esta figura mostra as retas ajustadas para estas duas regiões. Nota-se que o comportamento em baixa temperatura é similar em ambos os casos, indicando que a condutividade ocorre por processos similares e, praticamente, independente da frequência. Por outro lado, na região de temperaturas intermediárias, os valores das energias de ativação são distintos, correspondentes a 1,16 e 1,22 eV, o que indicam estar associados às mobilidades eletrônica e iônica, respectivamente. A redução da energia de ativação está associada com o aumento da temperatura e da frequência, o valor associado ao movimento eletrônico $(1,16 \mathrm{eV})$ é menor do que o valor associado ao movimento iônico $(1,22 \mathrm{eV})$.

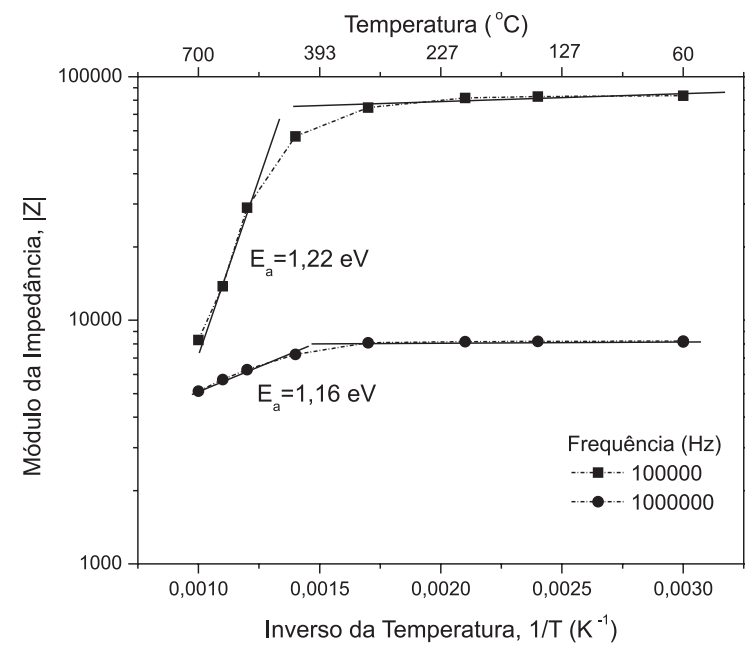

Figura 6. Efeito da temperatura sobre o módulo da impedância para valores de frequência de 0,1 e 1,0 MHz para zircônia estabilizada com ítria operando entre 25 e $700{ }^{\circ} \mathrm{C}$

Os resultados obtidos para a energia de ativação, calculados através da relação de Arrhenius, para a corrente alternada $(1,22 \mathrm{eV})$ e a corrente contínua $(1,25 \mathrm{eV})$ se aproximam. Esses valores também se aproximam dos dados reportados na literatura, dos quais a energia de ativação para o YSZ está na faixa de 0,90 a 1,20 eV, dependendo da composição das amostras e do método de produção/sinterização. ${ }^{9,10}$

Os resultado das medições de resistência e impedância não apresentam variações bruscas nos sinais elétricos, descontinuidades dos dados adquiridos, sub ou sobre-tensõoes do sinal de entrada do espectro de impedância, nem ruídos acentuados e não usuais. Foram medidas, aproximadamente, 10 amostras cerâmicas distintas, sem ter havido necessidade de manutenção, fazendo-se apenas o polimento da superfície do eletrodo e a troca de alguns discos cerâmicos. Isto indica que o porta-amostra aqui apresentado tem as características mecânicas e elétricas e desempenho adequados para a caracterização de amostras de cerâmicas condutoras para temperaturas de até $700{ }^{\circ} \mathrm{C}$.

\section{CONCLUSÕES}

Neste estudo foi desenvolvido e testado um porta-amostra para suportar amostras na forma de discos de materiais cerâmicos no interior de fornos, visando sua caracterização elétrica em temperaturas de até $700^{\circ} \mathrm{C}$. Os resultados obtidos nos testes realizados com zircônia estabilizada com ítria, usando corrente-tensão contínuas e alternadas demonstram que até $700^{\circ} \mathrm{C}$ o porta-amostra permite obter resultados de resistência, resistividade e impedância coerentes e livres de ruídos e descontinuidades. Além disso, os resultados de energia de ativação no processo de condução da YSZ obtidos são comparáveis com os reportados na literatura. $\mathrm{O}$ equipamento desenvolvido oferece precisão satisfatória, requer pouca manutenção e seu custo, ao contrário dos porta-amostras comerciais que usam alumina e platina, permite a montagem e operação sem que a unidade de pesquisa e/ou ensino tenha que fazer apreciável investimento.

\section{AGRADECIMENTOS}

Ao apoio financeiro concedido pelo CNPq (55.0479/2005-8, 474956/2008-3 e 308863/2007-0). S. D. da Nóbrega agradece à CAPES pela bolsa de mestrado concedida. I. M. Pepe e L. C. Simões Soares Jr. agradecem o apoio da FAPESB.

\section{REFERÊNCIAS}

1. Han, M.; Tang, X.; Yin, H.; Peng, S.; J. Power Sources 2007, 165, 757.

2. Irvine, J. T. S.; Konysheva, E.; Besmehn, A.; Solid State Ionic 2008, 179, 1432.

3. Murray, E. P.; Yeh, A. H.; McNamara, J. F.; J. Eur. Ceram. Soc. 1999, $14,454$.

4. Murray, E. P; Tsai, T.; Barnett, S. A.; Nature 1999, 400, 649.

5. Minh, N. Q.; J. Am. Ceram. Soc. 1993, 76, 563.

6. MacDonald, J. R.; Impedance Spectroscopy: Emphasizing Solid Materials and Systems, Wiley Interscience: New York, 1987.

7. Lai, W.; Haile, S. M.; J. Am. Ceram. Soc. 2005, 88, 2979.

8. Petitjean, M.; Caboche, G.; Siebert, E.; Dessemondb, L.; Dufour, L. C.; J. Eur. Ceram. Soc. 2005, 25, 2651.

9. Bauerle, J. E.; J. Phys. Chem. Solids 1969, 30, 2657.

10. Bauerle, J. E.; Hrizo, J.; J. Phys. Chem. Solids 1969, 30, 565.

11. Xin, X. Z. L.; Ding, Z.; Huang, X.; Liu, Z.; Sha, X.; Zhang, Y.; Su, W.; J. Alloys Compd. 2006, 425, 69. 